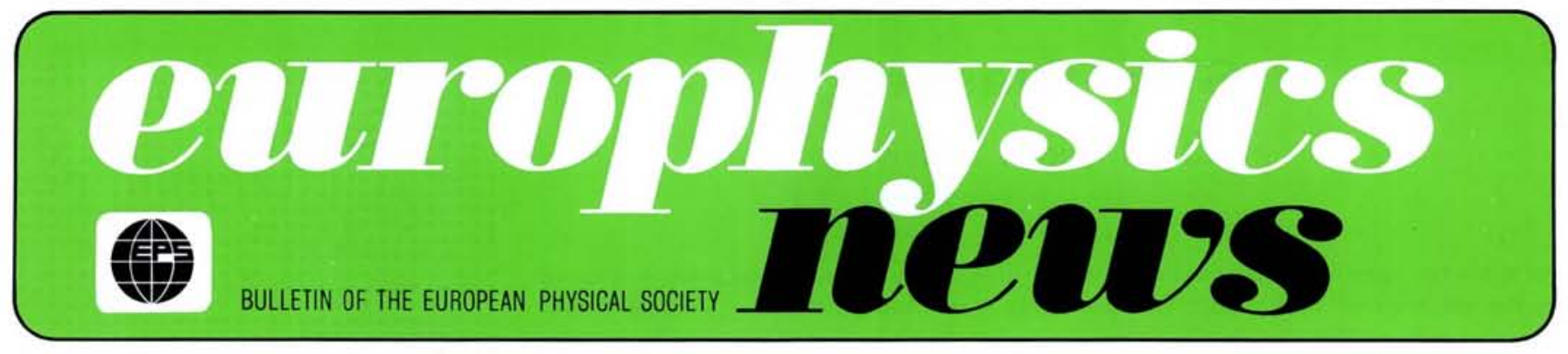

J.A.

Volume 14

Number 12

December 1983

\section{Welcome to Prague}

\section{Jan Kaczer \\ (Chairman of the Local Organizing Committee)}

The next general conference of the EPS, the sixth since the establishment of our Society will be held in Prague in August next year in collaboration with the Union of Czechoslovak Mathematicians and Physicists, one of the oldest professional societies in Europe.

Although initially there was some scepticism over the usefulness of such ventures the extraordinary interest shown by the European physics community, expressed by nearly 1000 preliminary registrations, received from physicists employed in academic, educational and applied physics establishments, proves to the contrary. The general conferences of the EPS have become an institution and are here to stay.

It will not be easy for Prague to uphold the standards of the previous conferences. Florence, Wiesbaden, Bucharest, York, Istanbul were all outstanding events and will be hard to out-do. The aim of the general, in contra-distinction to the specialized conferences, is to present an overview of the present state of the art of a significant part of physics, at a level which is comprehensible to all physicists. It is, inter alia, an educational event. In this highly specialized world of ours such a "brush up your modern physics" will be instrumental not only in widening our professional outlook but also in igniting the spark of interdisciplinary cognition.

A further objective of our general conferences is indicated by their title "Trends in Physics". They open up to young physicists the present and possible future development of physics and can greatly help them to choose a progressive field of physics to work in. Another very important task relates to the physicists coming from industrial laboratories. The conferences serve partly to widen their outlook and partly to give them prognoses of the "shape of things to come", since many scientific discoveries have been the fore-runners of important technical applications.

Last, but not least, is the social aspect of the general conferences which is to bring together physicists of different countries and to promote, through personal contact, international understanding not only in physics but also in other spheres of human activity.

We hope that Prague, a city in the heart of Europe, at the cross-roads of east and west and north and south will not fail in any respect. The tradition of this city in both the arts and sciences is of long standing. The university founded in 1348 by Charles IV, King of Bohemia and Emperor of the Holy Roman Empire, is one of the oldest in Europe. The city on the banks of the Vltava (Moldau) is famous not only for Smetana and Dvorak who were Czech and belong to Prague, but also for Mozart who composed and had first presented his Don Giovanni here; for Bolzano too, who was not only a great mathematician but also a great human thinker and philosopher and who found refuge in this city.

Prague is the city where Tycho Brahe and Kepler collaborated to help open up the modern views on our solar system and the Universe, the city where Einstein laid the foundations of the general theory of relativity. These facts are probably quite well known; less known is that Mach, Doppler and a number of other well-known physicists worked here for many years. Among worldrenowned Czech writers we want to name only two: J. Hassek who is the author of The Good Soldier Svejk, a wellknown antiwar classic and, of course, $\mathrm{K}$. Capek a very prolific writer who, among others, coined the term "Robot" in his famous play RUR (Rossum Universal Robots).

In other respects too, Prague can offer the visitor a great many distractions. Although the city was many times besieged and even occupied it was very lucky never to have been destroyed to any real extent. Its historical core is practically as it was hundreds of years ago. There are still a few romanesque and quite a number of gothic churches and other buildings. Here and there you will find some in renaissance style, but most of the historic part is made up of baroque castles, houses of worship and other buildings. In a later style there are a number of beautiful edifices in Jugendstil while among the painters of that period Alfons Mucha is our best known representative.

Before ending this list of extraconference pastimes I should like to touch upon Czech cuisine. At large hotels and better restaurants you can of course eat many types of international food at respectable prices. But there are a large number of very reasonable small Czech restaurants and pubs where you will be able to taste food specific to our country. And before I forget, wash it down with our exquisite Pilsen beer.

These are only a few of the attractions for those who will visit Prague on the occasion of the 6th General Conference. Needless to say, the greatest attraction will, of course, be the conference itself.

\section{Contents}

Welcome to Prague

Spin-Glasses

In Honour of the Stars and the Universe

Criteria of Choice for R,D and D

Support by the EC

New Members of EPS

Mechanical Instabilities of Metals

Solar Physics Elections

1
2
5
7
8
10
12

1 12 